\title{
Alianças estratégicas e o Terceiro Setor: uma análise sob a ótica do Objetivo de Desenvolvimento Sustentável 17
}

\author{
Strategic alliances and the Third Sector: an analysis from the perspective of the Sustainable
}

Development Goal 17

Las alianzas estratégicas y el Tercer Sector: un análisis desde la perspectiva del Objetivo de Desarrollo Sostenible 17

Recebido: 05/03/2021 | Revisado: 11/03/2021 | Aceito: 17/03/2021 | Publicado: 23/03/2021

\author{
Daniela Costa Pinheiro \\ ORCID: https://orcid.org/0000-0002-4763-7389 \\ Faculdade Cearense, Brasil \\ E-mail: danielacosta7@yahoo.com.br \\ Carlos Dias Chaym \\ ORCID: https://orcid.org/0000-0002-8685-4650 \\ Faculdade Cearense, Brasil \\ E-mail: cchaym@ faculdadescearenses.edu.br \\ Victor Hugo Fernandes de Almeida Ferreira \\ ORCID: https://orcid.org/0000-0003-4296-6594 \\ Centro Universitário Maurício de Nassau, Brasil \\ E-mail: victorhugofernandes@gmail.com \\ Maria Alcilene Morais \\ ORCID: https://orcid.org/0000-0002-5128-8230 \\ Universidade Federal do Ceará, Brasil \\ E-mail: moraisalcilene8@gmail.com \\ Rubens Carlos Rodrigues \\ ORCID: https://orcid.org/0000-0001-7563-6183 \\ Universidade de Fortaleza, Brasil \\ E-mail: rubensrodrigues@edu.unifor.br
}

\begin{abstract}
Resumo
O objetivo principal desse artigo é elencar as alianças estratégicas em uma organização do Terceiro Setor, considerando o Objetivo de Desenvolvimento Sustentável 17, como fontes de recursos para fortalecer a instituição através de seus parceiros da sociedade civil. Para isto, foi elaborado um referencial teórico sobre definição e teorias de alianças estratégicas, definição do Terceiro Setor e análise do Objetivo de Desenvolvimento Sustentável 17. A abordagem adotada foi de caráter exploratória e descritiva qualitativa. Para coleta de dados, foi adotado um questionário no estilo survey, no qual são coletadas informações preliminares da instituição, e foram realizadas entrevistas com roteiros semiestruturados, tratando-se de um estudo de caso de um projeto específico desenvolvido pela entidade. Os resultados apontaram que a instituição estudada realiza com êxito suas estratégias para consolidar as alianças com seus parceiros, motivando cada vez mais essa relação.
\end{abstract}

Palavras-chave: Alianças estratégicas; Terceiro setor; Objetivo de desenvolvimento sustentável 17.

\begin{abstract}
The main objective of this article is to list the strategic alliances in a Third Sector organization, considering Sustainable Development Objective 17, as sources of resources to strengthen the institution through its civil society partners. To this end, a theoretical framework was developed on the definition and theories of strategic alliances, a discussion about the Third Sector has been included and the analysis of the Sustainable Development Goals 17. The approach adopted was exploratory and qualitative descriptive. For data collection, a survey-style questionnaire was adopted, in which preliminary information from the institution is collected, and interviews were conducted with semistructured scripts, being a case study of a specific project developed by the entity. The results has showed that the studied institution successfully carries out its strategies to consolidate alliances with its partners, increasingly motivating this relationship.
\end{abstract}

Keywords: Strategic alliances; Third sector; Sustainable development goal 17.

\section{Resumen}

El objetivo principal de este artículo es relacionar las alianzas estratégicas en una organización del Tercer Sector, considerando el Objetivo de Desarrollo Sostenible 17, como fuentes de recursos para fortalecer la institución a través de sus socios de la sociedad civil. Para ello, se desarrolló un marco teórico sobre la definición y teorías de las alianzas 
estratégicas, se ha incluido una discusión sobre el Tercer Sector y el análisis de los Objetivos de Desarrollo Sostenible 17. El enfoque adoptado fue exploratorio y descriptivo cualitativo. Para la recolección de datos se adoptó un cuestionario estilo encuesta, en el cual se recolecta información preliminar de la institución y se realizaron entrevistas con guiones semiestructurados, siendo un estudio de caso de un proyecto específico desarrollado por la entidad. Los resultados han demostrado que la institución estudiada lleva a cabo con éxito sus estrategias para consolidar alianzas con sus socios, motivando cada vez más esta relación.

Palabras clave: Alianzas estratégicas; Tercer sector; Objetivo de desarrollo sostenible 17.

\section{Introdução}

Embora a maioria das organizações da economia capitalista contemporânea vise ao lucro, nem todas têm como finalidade o ganho financeiro. Algumas organizações existem para que possam gerar melhorias para a sociedade ou para grupos específicos, as quais compõem o que se denomina de Terceiro Setor. Há também várias iniciativas que têm como objetivo a formulação de alianças estratégicas e a realização de parcerias multissetoriais entre empresas e entidades do terceiro setor, buscando solucionar desafios e enfrentar problemas sociais, constituindo uma rede de mobilização de recursos oriundos de diferentes atores da sociedade civil que cooperam entre si para juntos realizar determinados projetos de desenvolvimento.

A sociedade civil é dividida em Primeiro, Segundo e Terceiro Setor. O Primeiro Setor é composto por organizações do Governo (União, estados ou municípios), o Segundo Setor é composto pelas empresas privadas, e o Terceiro Setor, pelas associações sem fins lucrativos. A missão do Terceiro Setor é contribuir para o desenvolvimento de locais, onde o Estado ainda atua de forma insuficiente, através de ações solidárias, tendo um importante papel para a sociedade. Como não visam ao lucro financeiro, organizações do Terceiro Setor dependem fundamentalmente de doações da sociedade civil e da iniciativa privada ou de repasses de entidades governamentais. Ademais, valem-se de um percentual considerável de mão de obra voluntária, composta por pessoas que doam seu tempo e suas habilidades para colaborar com a causa defendida pela organização.

Preocupações com o futuro do planeta e a manutenção da vida no longo prazo levaram a Organização das Nações Unidas (ONU) a realizar uma conferência em 2015 que reuniu os chefes de Estado dos países que a compõem para discutir os indicadores econômicos, sociais e ambientais dos últimos anos, elaborando como resultado o documento de apresentação dos novos Objetivos de Desenvolvimento Sustentável. Este documento elaborado pela ONU tem por nome "Transformando nosso mundo: a Agenda 2030 para o Desenvolvimento Sustentável”, sendo uma proposta de um plano global composto por 17 Objetivos de Desenvolvimento Sustentável (ODSs) e 169 metas, para que, ao executar esse plano, os seus 193 países membros aliassem desenvolvimento econômico e manutenção da vida no planeta para as gerações futuras.

A visão presente nos ODSs e em suas metas é ambiciosa, buscando transformar para melhor a situação do mundo, erradicando a pobreza, a fome e combatendo todas as formas de exclusão social e de degradação ambiental, visando diminuir o medo e a violência como fatores atuantes nas relações entre pessoas e nações, implementando a cooperação e o uso eficiente e sustentável dos recursos naturais, promovendo a dignidade humana em primeiro lugar e a responsabilidade socioambiental como princípios norteadores de programas, projetos e ações de desenvolvimento sustentável.

Cada ODS e suas respectivas metas tratam de dimensões, temáticas, problemas e, também, de questões específicas diferentes, as quais, por serem fundamentais para a viabilidade de uma sociedade sustentável, atuam entre si de maneira sistêmica e complementar, com interações, resultados e impactos multissetoriais. Todos os países membros da ONU assinaram a Agenda 2030 assumindo o compromisso de alcançar as metas dos 17 objetivos estabelecidos, junto aos seus governos, sociedade civil e outros parceiros.

Boa parte das ações das organizações do Terceiro Setor se constitui na busca pela formulação de alianças estratégicas e realização de parcerias multissetoriais com stakeholders, visando garantir a mobilização de recursos necessários para o cumprimento de seus projetos. Assim, o modo como as organizações do Terceiro Setor supera os desafios de sobreviver com recursos escassos, passando pela criação de alianças estratégicas, é capaz de se conectar com a proposta de um 
desenvolvimento sustentável, especialmente com o Objetivo de Desenvolvimento Sustentável 17, que versa sobre o fortalecimento dos meios de implementação e revitalização de parcerias.

A meta 17.17 do ODS-17 propõe: Incentivar e promover parcerias públicas, público-privadas e com a sociedade civil eficazes, a partir da experiência das estratégias de mobilização de recursos dessas parcerias. Os objetivos e as metas presentes na Agenda 2030 se constituem em uma proposta global, entretanto ela se destina a nortear as políticas, as estratégias de atuação, os programas, os projetos e as ações em âmbito nacional, regional e local, como bem atesta o documento Relatório Nacional Voluntário sobre os Objetivos de Desenvolvimento Sustentável, elaborado pela Secretaria de Governo da Presidência da República e pelo Ministério do Planejamento, Desenvolvimento e Gestão, com a supervisão da Casa Civil da Presidência da República e da Secretaria de Comunicação Social da Presidência da República, em 2017, com o apoio do Programa das Nações Unidas para o Desenvolvimento (PNUD) para a sua tradução e publicação.

Desta forma, a participação da sociedade civil, em todos os níveis de interação, desde a elaboração de diagnósticos situacionais e de projetos, passando pela execução, avaliação de impactos e resultados, formação de alianças estratégicas e de redes de cooperação institucional com variados stakeholders, até o financiamento de iniciativas, é essencial para o cumprimento da Agenda 2030. Portanto, organizações sem fins lucrativos possuem papel fundamental para a realização dessa meta, já que buscam gerar melhorias para a sociedade ou para grupos específicos, tendo o capital como meio e não como fim. O recorte empírico de aliança estratégica e de um projeto realizado em parceria multissetorial e cooperação por duas ou mais instituições da sociedade civil cearense, o qual se descreve e analisa na presente pesquisa, tem como origem o trabalho da Fundação Cultural Educacional Popular em Defesa do Meio Ambiente (Fundação CEPEMA).

Em 1989, foi criado o Centro de Educação Popular em Defesa do Meio Ambiente (CEPEMA), na cidade de Sobral, estado do Ceará, com apoio da ONG sueca Framtidsjorden (Terra do Futuro). Em janeiro de 1990, o Centro foi transformado na Fundação Cultural Educacional Popular em Defesa do Meio Ambiente, fazendo também parte da Rede Internacional Terra do Futuro. A Fundação CEPEMA vem trabalhando com a divulgação das técnicas da agricultura ecológica, principalmente na realização de cursos, dias de campo, seminários e assistência técnica rural e florestal, envolvendo os agricultores familiares e os assentados de reforma agrária.

Justifica-se a escolha dessa entidade pelo histórico de sua atuação na melhoria das condições de vida de várias populações locais do campo e da cidade, no estado do Ceará, cujo mérito teve um importante reconhecimento ao receber certificação nacional e internacional por produtos orgânicos importados e exportados. Instigado pela atuação da Fundação, o presente estudo tem como questão de pesquisa: Quais as principais alianças estratégicas em uma organização do Terceiro Setor, considerando o Objetivo de Desenvolvimento Sustentável 17? Analisar os elementos centrais que motivam as entidades da sociedade civil a realizar alianças e parcerias estratégicas para cumprir seu papel institucional constituiu o objetivo geral do presente estudo. Esse, por sua vez, será cumprido após a realização dos seguintes objetivos específicos: a) Caracterizar os principais fatores que motivam as organizações da sociedade civil a realizar parcerias estratégicas; b) Descrever as alianças estratégicas e de um projeto realizado em parceria multissetorial e cooperação de uma organização do Terceiro Setor; c) Correlacionar o caso de aliança estratégica institucional e de projeto social pesquisado com o Objetivo de Desenvolvimento Sustentável 17, tendo como escopo a sua meta 17.17.

O presente trabalho foi dividido nas seguintes seções: introdução, revisão da literatura, metodologia, análise dos resultados, considerações finais e referências.

\section{Metodologia}

A escolha dos procedimentos e caminhos metodológicos para este trabalho se justifica pela melhor adequação de suas características para a investigação do objeto de estudo, a análise da pergunta de pesquisa e os objetivos elencados, realizando- 
se uma pesquisa de natureza qualitativa, exploratória e descritiva (Pereira, Shitsuka, Parreira \& Shitsuka, 2018). Neves (1996, p. 1) afirma que a pesquisa qualitativa "compreende um conjunto de diferentes técnicas interpretativas que visam a descrever e a decodificar os componentes de um sistema complexo de significado. Tem por objetivo traduzir e expressar o sentido dos fenômenos do mundo social". Complementarmente, de acordo com Gil (1996, p. 45), a pesquisa descritiva "tem como objetivo primordial a descrição das características de determinada população ou fenômeno".

Investigou-se como nível de análise a dimensão organizacional de uma Organização da Sociedade Civil (OSC), tendo como unidades de análise incorporadas: a formação de alianças estratégicas de uma instituição da sociedade civil; as motivações e a atuação de stakeholders desta instituição, bem como a relação que esses formatam com a mesma; os impactos e os resultados organizacionais e específicos a partir de um projeto definido e executado por intermédio desta aliança estratégica; e, por fim, como a partir do que preceituam e orientam o ODS 17 e especialmente sua meta 17.17, ocorrem influências na dinâmica e nos sistemas de atuação institucional.

O desenho metodológico desse artigo utilizou, como método de investigação, o estudo de caso único incorporado (Yin, 2015), pesquisando empiricamente a configuração de uma rede de cooperação institucional da entidade da sociedade civil, a Fundação CEPEMA, focando um projeto social específico desenvolvido pela organização e seus stakeholders envolvidos na parceria correspondente ao mesmo.

O estudo de caso constitui-se como procedimento metodológico que viabiliza um recorte da realidade e de relações sociais complexas, propiciando ao investigador uma maior aproximação do fenômeno estudado, ampliando as possibilidades de obtenção de novas vias de compreensão e de análise do mesmo, o que ocorre pelo acúmulo de conhecimento empírico acerca do objeto de estudo. Gil $(1999$, p. 72) argumenta que o estudo de caso "é caracterizado pelo estudo profundo e exaustivo de um ou poucos objetos, de maneira a permitir o seu conhecimento amplo e detalhado, tarefa praticamente impossível mediante os outros tipos de delineamentos considerados".

Como assevera Martins (2006, p. 11), o método do estudo de caso "pode nortear na busca de explicações e interpretações convincentes para situações que envolvam fenômenos sociais complexos, e a construção de uma teoria explicativa do caso que possibilite condições para se fazerem inferências analíticas sobre proposições constatadas no estudo". Essa visão corrobora com Yin (2015, p. 24), para quem o estudo de caso "permite que os investigadores retenham as características holísticas e significativas dos eventos da vida real - como os ciclos individuais da vida, o comportamento dos pequenos, os processos organizacionais e administrativos, a mudança de vizinhança, o desempenho escolar, as relações internacionais e a maturação das indústrias".

Quanto aos objetivos desta pesquisa, ela se destina à produção de conhecimento analítico sobre a realidade de uma experiência empírica de uma OSC, descrevendo as variáveis presentes em uma aliança estratégica e suas características e impactos organizacionais. Portanto, o estudo de caso, por se caracterizar por procurar responder questões do tipo "como e por que", é o recurso metodológico ideal "quando o pesquisador tem pouco controle sobre os eventos e quando o foco se encontra em fenômenos contemporâneos inseridos em algum contexto da vida real” (Yin, 2015, p. 19).

\subsection{Procedimentos de coleta e análise de dados}

Um dos instrumentos mais úteis nos estudos de caso e em pesquisas exploratórias e descritivas são questionários no estilo survey e entrevistas com roteiros semiestruturados. Em consonância com a natureza qualitativa da pesquisa, a coleta de dados se deu em duas etapas: um questionário foi enviado e respondido por um diretor e uma assessora técnica da Fundação CEPEMA, durante o mês de maio de 2020, por intermédio de comunicação digital, via e-mail; a segunda etapa consistiu em entrevistas semiestruturadas com duração de 50 minutos, em profundidade com um gestor, sendo o diretor-presidente que 
conhece o funcionamento da instituição, e uma colaboradora que é assistente técnica, cuja função é acompanhar todos os processos dos projetos em execução da organização.

Quanto às entrevistas, essas foram utilizadas para detalhar as informações preliminares coletadas pelo questionário; realizaram-se, também, por meio virtual, utilizando-se de ferramentas digitais de comunicação de áudio e vídeo. Portanto, estes procedimentos, instrumentos e técnicas foram utilizados para a coleta de dados, além da análise documental interna e externa referente às alianças estratégicas estabelecidas com os stakeholders do projeto, cuja parceria foi objeto de investigação.

A análise de dados oriundos de documentos referentes ao ODS 17 e à sua meta 17.17 também foi objeto de escrutínio. Para a interpretação das informações coletadas e sua análise, realizou-se a conexão teórico-analítico-empírica, tendo como lastro os conhecimentos apresentados nos referencias teóricos presentes na revisão de literatura. Como forma de tratamento e análise dos dados, as entrevistas foram gravadas em áudio e vídeo, posteriormente transcritas, para serem avaliadas por meio da análise de conteúdo (Bardin, 2016).

\subsection{Abordagem temporal da pesquisa e aspectos éticos}

O presente artigo descreve o processo de formação e gestão de alianças estratégicas horizontais, tendo sua abordagem temporal definida como um estudo transversal. Conforme Jung (2003), nas pesquisas transversais, os dados são coletados em um único momento no tempo, buscando um recorte temporal momentâneo dos fenômenos investigados. Os protocolos éticos que orientam o zelo com o sigilo das informações e o anonimato com referência aos informantes foram observados na condução da pesquisa, solicitando e obtendo todas as permissões necessárias.

\section{Referencial Teórico}

A literatura acadêmica e as linhas teóricas acerca de alianças estratégicas na sociedade civil constituem um campo de estudo bastante amplo; há grande número de estudos de cases de sucesso sobre as mais diversas interfaces e parcerias entre setor público, privado e terceiro setor. Entretanto, pesquisas que abordem a estruturação de redes de cooperação institucional, seus stakeholders e as alianças estratégicas constituídas, levando em conta as diretrizes e metas da Agenda 2030 para o Desenvolvimento Sustentável e seus respectivos 17 ODS's, ainda precisam de maior aprofundamento teórico e vislumbram novas perspectivas para a administração contemporânea, com a possibilidade de analisar fontes de experiências inovadoras e de avaliar approaches e metodologias de gestão criados destas iniciativas.

Assim, na revisão teórica aqui apresentada, aborda-se a teoria e o conceito de aliança estratégica; a definição de organizações do Terceiro Setor e a avaliação da qualidade de suas estratégias e relações de parcerias, o engajamento com stakeholders e a mobilização de recursos multissetoriais em projetos com organizações do Terceiro Setor; e, por último, os princípios da Agenda 2030 para o Desenvolvimento Sustentável, analisando, especificamente, o Objetivo de Desenvolvimento Sustentável 17 e sua meta 17.

\subsection{Teoria e conceito de aliança estratégica}

Com a intensificação da globalização em todas as áreas - intercâmbio de conhecimentos, comércio global de mercadorias e serviços, movimentações permanentes de pessoas entre países, formação de redes internacionais de cooperação governamentais e de entidades da sociedade civil, houve um exponencial crescimento da relevância dos estudos sobre alianças estratégicas, tanto em nível da administração organizacional e de gestão de parcerias, como também para o planejamento de empresas, governos e instituições do Terceiro Setor (Vale \& Lopes, 2010).

Apesar disto, referenciais teóricos mais consistentes que tratem de examinar alianças estratégicas nacionais ainda são escassos no Brasil, isto se torna mais observável quando se buscam pesquisas e estudos de caso, que abrangem stakeholders de 
setores distintos - Primeiro, Segundo e Terceiro Setor atuando em sinergia com um determinado projeto - e alianças estratégicas que sejam mobilizadoras de múltiplos atores sociais e recursos multissetoriais. Uma das formas de se analisar alianças estratégicas, seja em nível internacional, nacional, regional ou mesmo local, é por meio da teoria de aprendizagem organizacional, pois, em qualquer aliança estratégica e consolidação de parcerias mais amplas, o repasse e a troca de conhecimentos, assim como de tecnologias de gestão das organizações, são premissas para o seu êxito.

Segundo Osland e Yaprak (1995 apud Klotzle, 2002) ao aprender uns com os outros, os parceiros assimilam novos conceitos de estrutura organizacional e apreendem novas formas de cultura organizacional. $\mathrm{O}$ foco no desenvolvimento organizacional, o planejamento estratégico das organizações e a avaliação de impactos e resultados dos projetos são exemplos de intercâmbio de conhecimentos, habilidades e competências que instituições do Terceiro Setor aprenderam com empresas parceiras e organismos governamentais.

Assim como, em contrapartida, a dinâmica do trabalho e a missão das organizações não governamentais ensinaram a governos e empresas a importância do capital social, da ampliação de tecnologias sociais de sucesso para um número maior de pessoas e lugares, do envolvimento e da participação das comunidades para o êxito de projetos, da capacidade de selecionar iniciativas que tenham o potencial de serem replicadas com resiliência (Alves, 2002; Falconer, 1999, Morais; Sizenando-Filho; Santos; \& Ismael, 2016).

$\mathrm{Na}$ linha teórica dos recursos empresariais e considerando o risco, Das e Teng (1998) analisaram as metas e os objetivos dos stakeholders e parceiros envolvidos na criação de uma parceria estratégica, classificando quatro possíveis modelos de recursos que podem ser complementares de forma simultânea ou não, colaborando para estabelecer uma aliança estratégica: são os recursos financeiros, tecnológicos, físicos e organizacionais.

Desta forma, os tipos de recursos com os quais as organizações contribuem para formar uma aliança tornam-se variáveis fundamentais para compreender as metas e os objetivos, que estimulam e determinam sua criação, propiciando a existência de uma constelação de interesses e contrapartidas. Uma síntese dos conceitos de aliança estratégica que embasam este artigo está apresentada no Quadro 01, conforme a perspectiva teórica que fundamenta essa pesquisa. 
Quadro 1. Definições de aliança estratégica.

\begin{tabular}{|c|c|}
\hline Autores & Definição de aliança estratégica \\
\hline $\begin{array}{l}\text { Contractor e Lorange } \\
\text { (1988) }\end{array}$ & $\begin{array}{l}\text { Alianças estratégicas são realizações de acordos de cooperação entre duas ou mais } \\
\text { organizações como forma de negociação em que os parceiros compartilham esforços } \\
\text { em áreas como administração, transferência de tecnologia, fontes de financiamento e } \\
\text { mercado, de forma que ambas as partes sejam beneficiadas. }\end{array}$ \\
\hline Badaracco (1991) & $\begin{array}{l}\text { As alianças são arranjos organizacionais e políticas operacionais por meio dos quais as } \\
\text { organizações separadas compartilham uma autoridade administrativa, formam relações } \\
\text { sociais e aceitam uma propriedade conjunta, e que os arranjos contratuais específicos } \\
\text { são substituídos por uma forma mais flexível de administrar. }\end{array}$ \\
\hline Teece (1992) & $\begin{array}{l}\text { Acordos por meio dos quais dois ou mais parceiros dividem o compromisso de } \\
\text { alcançar um objetivo comum, unindo todas as suas capacidades e recursos e } \\
\text { coordenando suas atividades [...]. }\end{array}$ \\
\hline Kanter (1994) & $\begin{array}{l}\text { As alianças estratégicas são relacionamentos que envolvem benefícios para todos os } \\
\text { parceiros e colaboração mútua, como forma de criar valor e infraestrutura, para } \\
\text { facilitar a aprendizagem. }\end{array}$ \\
\hline Das e Teng (1998) & $\begin{array}{l}\text { Conceituam as alianças estratégicas como sendo acordos de cooperação entre firmas } \\
\text { por meio dos quais os parceiros visam atingir objetivos estratégicos previamente } \\
\text { definidos. }\end{array}$ \\
\hline $\begin{array}{l}\text { Harbison e Pekar Jr. } \\
\text { (1999) }\end{array}$ & $\begin{array}{l}\text { Alianças estratégicas podem descrever uma gama ampla dos relacionamentos que se } \\
\text { encontram dentro desses extremos, desde projetos de curto prazo, passando por } \\
\text { relacionamentos de longo prazo entre um fornecedor e um fabricante, até amplas } \\
\text { alianças estratégicas em que parceiros acessam as capacidades um do outro e aprendem } \\
\text { a partir dessa troca. }\end{array}$ \\
\hline Lima e Filho (2009) & $\begin{array}{l}\text { As alianças estratégicas são estruturas versáteis e evolutivas de cooperação entre } \\
\text { organizações. }\end{array}$ \\
\hline Aaker (2001) & $\begin{array}{l}\text { As alianças estratégicas são definidas como sendo a colaboração entre duas ou mais } \\
\text { organizações, no intuito de potencializar suas forças para que alcancem metas } \\
\text { estratégicas. }\end{array}$ \\
\hline Austin (2001) & $\begin{array}{l}\text { As alianças estratégicas são instrumentos para a alavancagem das competências de } \\
\text { cada parceiro e para a criação de valor de mão dupla e podem envolver múltiplos } \\
\text { parceiros num esforço para reunir recursos mais abundantes e combinações de } \\
\text { competências mais vigorosas. }\end{array}$ \\
\hline Eiriz (2001) & $\begin{array}{l}\text { Uma aliança estratégica ocorre quando duas ou mais organizações decidem conjugar } \\
\text { esforço para perseguirem um objetivo estratégico comum. }\end{array}$ \\
\hline Inkpen (2003) & $\begin{array}{l}\text { Arranjos organizacionais colaborativos que usam recursos e/ou estruturas de } \\
\text { governança de mais de um parceiro. }\end{array}$ \\
\hline $\begin{array}{l}\text { Troccoli e Soares } \\
\text { (2003) }\end{array}$ & $\begin{array}{l}\text { A aliança estratégica pode ser definida como um relacionamento estabelecido entre } \\
\text { duas ou mais partes, que visa um compartilhamento do conhecimento e de outros } \\
\text { recursos, que possa ser benéfico para todos os envolvidos. }\end{array}$ \\
\hline Noleto (2004) & $\begin{array}{l}\text { Alianças estratégicas envolvem a cooperação entre duas ou mais entidades. } \\
\text { Representam um meio de as instituições manterem suas estratégias individuais, apesar } \\
\text { dos recursos limitados em algumas áreas, e fortalecerem-se ao encontrar outras } \\
\text { organizações com as quais possam cooperar. Representam uma importante forma de } \\
\text { cumprir a missão e atingir objetivos de transformação social e econômica. }\end{array}$ \\
\hline
\end{tabular}

Fonte: Adaptado de Viana (2013) e Klotzle (2003)

Para Klotzle (2003) é possível se distinguir entre essas várias definições de aliança estratégica, uma abordagem teórica com uma perspectiva mais abrangente sobre o que se constitui como uma aliança estratégica, conceitualizando-a como multifacetadas constelações de parcerias e diversos possíveis níveis de cooperação entre organizações, e uma outra linha de análise que trata do tema com uma determinação mais estrita do conceito, desconsiderando certas relações intraorganizacionais.

Adota-se, aqui, a visão mais abrangente do conceito de aliança estratégica, na qual as organizações realizam projetos em cooperação, com a finalidade de realizar objetivos e atingir metas, que, sem uma rede de cooperação institucional, 
poderiam ser inatingíveis, se atuassem de maneira isolada. Desta forma, o conceito de aliança estratégica, que fundamenta o approach aqui selecionado, tem como referenciais teóricos a vertente teórica dos recursos empresariais e a base conceitual das definições apresentadas no Quadro 1.

Os estudos teóricos sobre alianças estratégicas descortinam um rico veio analítico, o que possibilita diferentes tratamentos epistemológicos realizados pelas mais diferentes pesquisas acadêmicas na área da administração. Assim, é apresentado no Quadro 2 uma seleção das teorias que constituem o substrato das formulações desenvolvidas no presente artigo.

Quadro 2. Principais perspectivas teóricas sobre alianças estratégicas.

\begin{tabular}{|c|c|c|}
\hline $\begin{array}{c}\text { Perspectivas } \\
\text { teóricas }\end{array}$ & Contribuições para o entendimento das alianças estratégicas & Principais referências \\
\hline $\begin{array}{l}\text { Teoria } \\
\text { Contingencial }\end{array}$ & $\begin{array}{l}\text { Identificou diferentes variáveis contingenciais, que seriam as possíveis } \\
\text { causas que induzem ou motivam as organizações a estabelecerem } \\
\text { relações de cooperação, isto é, elas explicam as razões porque } \\
\text { organizações escolhem relacionar-se com outras. }\end{array}$ & $\begin{array}{l}\text { Oliver (1990); Morgan (2000); Morin } \\
\text { (2005) }\end{array}$ \\
\hline $\begin{array}{l}\text { Teoria da } \\
\text { Dependência de } \\
\text { Recursos }\end{array}$ & $\begin{array}{l}\text { Salientou, como um dos fortes condicionantes para a formação das } \\
\text { redes de cooperação, o compartilhamento de recursos tangíveis e } \\
\text { intangíveis. }\end{array}$ & $\begin{array}{l}\text { Pfeffer e Salancik (1978, 2003); Penrose } \\
\text { (1997); Peteraf (1997); Prahalad \& } \\
\text { Hamel (1997); Wernerfelt (1997) }\end{array}$ \\
\hline $\begin{array}{l}\text { Teoria da Ecologia } \\
\text { Populacional }\end{array}$ & $\begin{array}{l}\text { Focalizou a diversidade e a adaptação organizacionais dentro de uma } \\
\text { população de organizações que competem por recursos semelhantes } \\
\text { ou clientes afins, ela identificou diferentes fatores ambientais externos } \\
\text { como: turbulência política, regulamentação governamental, processos } \\
\text { tecnológicos, entre outros, que podem tanto influenciar no } \\
\text { crescimento e sobrevivência das organizações como levá-las ao } \\
\text { declínio. Incentivando assim, a inovação e a mudança numa } \\
\text { população de organizações para novas formas e tipos de organizações, } \\
\text { a fim de atender as necessidades do mercado por meio de iniciativas } \\
\text { empreendedoras. }\end{array}$ & $\begin{array}{l}\text { Freeman (1979); Cunha (1999); Caldas \& } \\
\text { Cunha (2005); Daft (2006); Baum (1999) }\end{array}$ \\
\hline $\begin{array}{l}\text { Teoria do } \\
\text { Aprendizado }\end{array}$ & $\begin{array}{l}\text { Destacou o importante papel das relações e parcerias dos diferentes } \\
\text { atores/empresas, como fonte de geração de novos conhecimentos, } \\
\text { fundamental para a competitividade. Nesta perspectiva a cooperação } \\
\text { permite deflagrar um processo de troca, adaptação e evolução das } \\
\text { organizações no mundo caracterizado por crescente complexidade e } \\
\text { rápidas mudanças tecnológicas. }\end{array}$ & $\begin{array}{l}\text { Polanyi (1958); Itami e Roehl (1987); } \\
\text { Kogut e Zander (1992); Inkpen (2006); } \\
\text { Larsson, Bentssson, Henriksson e Sparks } \\
\text { (1998); Kale, Singh e Perlmutter (2000) }\end{array}$ \\
\hline $\begin{array}{l}\text { Teoria Baseada em } \\
\text { Recursos }\end{array}$ & $\begin{array}{l}\text { Identificou que a cooperação que envolve diferentes organizações - } \\
\text { cada uma delas dotada de um conjunto específico de habilidades e } \\
\text { recursos - é capaz de distingui-las no mercado. }\end{array}$ & $\begin{array}{c}\text { Wernerfelt (1997); Haugstad (1999); } \\
\text { Prahalad e Hamel (1997); Penrose, 1997; } \\
\text { Peteraf, 1997 }\end{array}$ \\
\hline Teorias Estratégicas & $\begin{array}{l}\text { Destacou a configuração em redes de cooperação como fator } \\
\text { altamente estratégico para obtenção e manutenção de vantagens } \\
\text { competitivas. }\end{array}$ & $\begin{array}{l}\text { Astley e Fombrun (1983); Astley (1984); } \\
\text { Dyer \& Singh, (1998); Gulati, Nohria, \& } \\
\text { Zaheer (2000); Gulati, Nohria, \& Zaheer } \\
\text { (2000); Marcon \& Moinet (2000) }\end{array}$ \\
\hline
\end{tabular}

Fonte: Adaptado de Viana (2013), Balestrin e Vargas (2002) e Vale e Lopes (2010).

Busca-se neste estudo, de acordo com Balestrin e Vargas (2002), a implementação de algumas dessas abordagens teóricas, produzindo explicações complementares umas com as outras, considerando os estudos organizacionais sobre alianças estratégicas, focando nas compatibilidades existentes entre elas, principalmente, como demonstram Vale e Lopes (2010).

O estudo empírico realizado nessa pesquisa coordena suas análises, utilizando, primordialmente, as bases epistemológicas da teoria contingencial e da teoria baseada em recursos, conectando seus diferentes enfoques das características organizacionais de forma multifacetada e complementar. O esforço de pesquisa e de realização de estudos de casos são essenciais para a produção de conhecimento sistêmico sobre alianças estratégicas, procurando entender seus 
aspectos, o impacto desses modelos de gestão no ambiente das organizações parceiras, e as tendências geradas por essas formas de articulação organizacional e de criação de parcerias.

Segundo Brito (2008), o desenho institucional na formação de alianças pode envolver duas ou dezenas de entidades, ocorrendo no setor privado, no poder público e no Terceiro Setor, havendo a possibilidade de acontecer entre instituições do mesmo setor ou entre organizações de setores distintos, com duas possíveis modalidades de implementação, vertical ou horizontal. Isto torna o campo de estudos acerca de alianças estratégicas muito amplo e com variadas oportunidades de pesquisas inovadoras e investigações empíricas de cases de sucesso.

A dimensão dos governos, em todas as suas esferas, no estabelecimento de alianças estratégicas é bastante significativa. Portanto, analisar o potencial estratégico das relações institucionais de entidades do terceiro setor e os governos é um fator de grande relevância nas pesquisas sobre parcerias e stakeholders. Este estudo, logo, apresenta "olhares" sobre a importância da sustentabilidade financeira que organizações não governamentais podem obter dessa relação com o setor público, assim como acerca da colaboração que as instituições do Terceiro Setor podem aportar para os governos, no que concerne ao aprimoramento de políticas públicas e sociais nas mais diversas áreas, como educação, distribuição de renda e riqueza, saúde, habitação, alimentação, transporte, dentre outras.

Para Brito (2008), as alianças estratégicas e relações de cooperação institucional com o poder público podem ser de três tipos: a) público-público; b) público-privada; e c) público-social. Isto será considerado com mais detalhes quando for analisado mais adiante o Terceiro Setor e sua importante posição como ator social na formação de alianças estratégicas. A referida autora advoga que projetos sociais que são planejados e executados por intermédio de alianças estratégicas obtêm maior chance de êxito e de conseguir resultados de maior qualidade e abrangência. A maior proatividade é um elemento determinante para o maior sucesso de projetos realizados em alianças institucionais, assim como a abertura para o aprendizado mútuo, maior nível de inovação e disposição favorável dos parceiros atuando em conjunto, o que, por fim, constitui-se em um diferencial qualitativo e valor agregado às instituições e aos projetos (Brito, 2008).

Os projetos desenvolvidos, exclusivamente, por uma única entidade possuem possibilidades bem menores de obter resultados concretos, pois a complexidade e a abrangência das temáticas e questões sociais envolvidas nesses projetos exigem a constituição de um arco de alianças, parcerias e a aplicação de recursos de maneira complementar.

Uma última questão sobre a teoria e o conceito de alianças estratégicas diz respeito ao processo de governança na gestão das alianças, para que elas sejam bem-sucedidas e alcancem seus objetivos. Como as alianças estratégicas são acordos nos quais duas ou mais organizações assumem o compromisso de atingir objetivos comuns, complementando e aplicando suas capacidades e recursos (Teece, 1992), é essencial que, na gestão de alianças, os processos de governança coordenem, de forma interorganizacional, os fluxos de comunicação e as rotinas dos parceiros envolvidos, conciliando interesses e alinhando atividades para a execução exitosa dos projetos comuns (Dyer \& Kale, 2007; Schilke \& Goerzen, 2010).

\subsection{Terceiro setor: definição, avaliação e parcerias}

O termo Terceiro Setor, a evolução de suas definições conceituais, de seus marcos legais e sua história e surgimento compõem um rico manancial de estudos acadêmicos, com uma relevância significativa para o campo de pesquisa da administração contemporânea. De acordo com Melo Neto e Froes (2001), define-se o Terceiro Setor como um ambiente institucional privado, no qual existem ações voltadas para o bem-estar do coletivo, gerando bens e consumo, não havendo qualquer tipo de posse de excedentes econômicos e particulares no processo.

A definição de organizações do Terceiro Setor, sua atuação e a avaliação da qualidade de suas estratégias e relações de parcerias, bem como dos resultados alcançados por seus projetos e iniciativas influenciam as políticas públicas em todas as áreas e em todas as esferas da sociedade civil, em níveis locais, regionais, nacionais e internacionais (Fernandes, 1994). No que 
concerne também à administração e suas ferramentas de gestão, além de questões acerca da governança institucional, as práticas implementadas por organizações do Terceiro Setor têm colaborado para a inovação e o aprimoramento de estratégias de planejamento, técnicas gerenciais e de marketing, modelos de elaboração e avaliação de projetos, mantendo um profícuo diálogo com o setor empresarial e o governamental, propiciando uma interinfluência técnica, política e conceitual entre esses três setores.

Historicamente, o que mais impulsionou o surgimento e a ascensão do Terceiro Setor foi a crise do welfare state, que se iniciou por volta da década de 1970 do século passado, crise essa que se acentuou na década seguinte e se agravou drasticamente, expandindo-se globalmente nos anos 1990 do século XX. Como resultado, políticas econômicas neoliberais ganharam força hegemônica e terreno em países de todos os continentes, advogando a diminuição do poder, das funções, da presença e interferência do Estado na sociedade (Alves, 2002).

As consequências mais importantes do ideário neoliberal foram a retirada da atuação do Estado de várias áreas da economia, a redução de gastos sociais e a omissão estatal no desenho, na elaboração e na execução de políticas públicas de combate às desigualdades sociais. Neste cenário socioeconômico e político, as organizações do Terceiro Setor afloraram como uma resposta e alternativa para a crescente demanda por políticas sociais, em um primeiro momento, em conexão com a intensificação da importância do poder local na articulação e mobilização da sociedade civil para a defesa de interesses coletivos, de causas e temáticas setoriais; para o diagnóstico de problemas sociais e ambientais locais; e, para a elaboração e a execução de projetos e ações, grande parte deles incentivados pelo suporte financeiro e apoio técnico oriundos de organismos internacionais e de órgãos de cooperação multilateral e bilateral (Falconer, 1999).

Segundo Salamon (1997), outro fator propulsor da ascensão do Terceiro Setor foi a emergência da vontade do cidadão comum de participar como ator social na esfera pública, discutindo, decidindo e influenciando nos rumos de sua comunidade, procurando identificar problemas existentes em seu entorno social e assumindo uma postura ativa na solução dos mesmos, mobilizando outros grupos de pessoas, agindo de maneira coletiva e suprindo o vácuo deixado pelo Estado, cujo papel foi diminuído como agente de formulação e de intervenção socioeconômicas.

É, exatamente, nesse contexto histórico - no qual o Estado e a atuação estatal perdem força na sociedade - que as organizações do Terceiro Setor ganharam espaço social e político de considerável relevância, como agentes de enfrentamento de problemas sociais, econômicos e ambientais, o que tem sido consolidado e se intensificado no século XXI, constituindo-se em um fenômeno com abrangência em múltiplos níveis, tanto local, nacional, tanto quanto global.

O termo Terceiro Setor teve sua utilização iniciada nos anos 1970 do século passado nos Estados Unidos da América, tendo como parâmetro a existência de organizações de natureza jurídica privada, as quais não possuíam o lucro como finalidade, tendo como missão a criação ou a distribuição de bens e serviços públicos, abrangendo, assim, a noção de público como sendo algo não apenas referenciado no que é estatal, ou seja, um conceito ampliado da definição tradicional do que se entendia como público, a saber, o público não-estatal (Falconer, 1999). O termo tem como referência conceitual também a analogia com a divisão clássica da economia em setores, sendo o primeiro setor o Estado e o segundo setor o mercado.

Avaliando-se essas bases conceituais supracitadas, observa-se que o Terceiro Setor inclui grande número de instituições que atuam nas mais diversas áreas temáticas, tendo como características essenciais que elas são formadas por agentes privados, não tendo fins lucrativos, exercendo atividades de finalidade pública (Fernandes, 1994). Apesar de existirem outras nomenclaturas, que se referem a entidades que se adequam à definição apresentada no parágrafo anterior - como, por exemplo, organizações sociais, organizações da sociedade civil de interesse público e entidades filantrópicas, havendo inclusive, no que se refere a estes exemplos, seus respectivos regramentos jurídicos específicos - o termo Terceiro Setor é o mais usado no Brasil (Alves, 2002; Bresser-Pereira \& Grau, 1999; Falconer, 1999; Salamon, 1997). 
Ao se efetivar uma avaliação sobre o espectro de atuação das organizações que se inserem no Terceiro Setor, verificase que ele é bastante amplo, englobando diversas áreas e temáticas, como, por exemplo, atividades de promoção da saúde e de atendimento médico-hospitalar; projetos de fomento ao desenvolvimento econômico local; ações de incentivo à prática do voluntariado; iniciativas de proteção do meio ambiente; experiências diretas de realização de serviços sociais e de apoio jurídico a comunidades; ações jurídicas, programas de proteção e campanhas educacionais e de comunicação, que articulam a defesa dos direitos civis, políticos e econômicos de minorias sociais e de segmentos populacionais, socialmente desprotegidos ou culturalmente perseguidos ou marginalizados, dentre tantas outras exemplaridades, que compõem a abrangência da atuação do Terceiro Setor na sociedade civil (Falconer, 1999; Fernandes, 1994).

Segundo Falconer (1999), outra questão a ser avaliada em relação ao Terceiro Setor é a que se relaciona com a perspectiva da governança e da gestão organizacional. A governança, na maior parte das entidades que compõem o Terceiro Setor, está ainda na fase de ampliação da sua profissionalização, buscando a adoção de boas práticas institucionais, a definição de estratégias claras e eficientes de sustentabilidade financeira e o planejamento da mobilização e articulação de parcerias mais estáveis para a execução de suas atividades. No que concerne à gestão, apresenta-se como principal necessidade a intensificação da formação técnica dos seus gestores, em todos os níveis das organizações - tanto no nível de direção e tomada de decisão, como nos níveis de gerenciamento, execução e avaliação de resultados - desenvolvendo, assim, a competência técnico-gerencial dos seus quadros, em todas as dimensões da gestão organizacional: a estratégica, a tática e a operacional (Salamon, 1997).

Por fim, a estratégia premente que as organizações do Terceiro Setor podem adotar como um sistema de aprimoramento da gestão, da capacidade de articulação institucional na captação e manutenção de parcerias, e da sustentabilidade financeira e sobrevivência organizacional deve levar em consideração a avaliação da qualidade dos serviços ou bens públicos por elas fornecidos e as maneiras como elas se relacionam com seus parceiros, assumindo a responsabilidade perante eles de realizar a prestação de contas de suas atividades, de avaliar os resultados alcançados e de ter, como cultura organizacional, a transparência da sua atuação e a publicidade das suas ações feitas por intermédio de uma comunicação democrática.

Essa responsabilidade das organizações do Terceiro Setor, em respeitar os seus parceiros, apresentando em detalhes como foram geridos os variados recursos envolvidos nas parcerias e quais os impactos e resultados gerados, é um aspecto crucial e determinante da sobrevivência, longevidade ou não da instituição.

\subsection{Análise da influência e da importância estruturante do Objetivo de Desenvolvimento Sustentável 17}

O caráter multidimensional e as interconexões dos problemas sociais, ambientais, educacionais, econômicos e populacionais a serem enfrentados exigem a constituição, a articulação e a mobilização de redes de atores capazes de complementar esforços institucionais, usar com maior eficácia e resiliência os recursos disponíveis e atuar de forma mais capilarizada.

Portanto, para implementar programas, projetos e ações da Agenda 2030 na realização efetiva de alianças estratégicas para o desenvolvimento sustentável, faz-se necessária a ação integrada e sinergética que abranja diversos setores da sociedade civil e as várias esferas de governos (Brasil, 2017). As organizações não governamentais compõem um dos grupos mais relevantes para esse tipo de atividade.

Os ODSs apenas serão realizados mediante uma concertação local, regional, nacional e internacional, que tenha como finalidade renovar o compromisso de cooperação interinstitucional entre as organizações públicas, privadas e do Terceiro Setor, colocando o foco no desenvolvimento das comunidades por intermédio de parcerias e alianças amplas, as quais incluam todos os setores interessados e as pessoas afetadas pelos processos, programas e projetos de desenvolvimento. Os meios de 
implementação e as parcerias para o desenvolvimento sustentável buscam instituir a junção de esforços organizacionais, de capital social e de recursos multissetoriais, em todas as dimensões temáticas possíveis. Além de ser fundamental, o fomento à prática de parcerias multilaterais, no caso específico do Brasil, para o crescimento sustentado, a cooperação Sul-Sul, deve nortear as iniciativas e os projetos.

O ODS 17 da Agenda 2030 é o que trata destas questões de estabelecimento de parcerias, de redes de cooperação institucional e de alianças estratégicas entre as organizações, propondo, para tanto, a transferência de tecnologias materiais e sociais, e o intercâmbio de dados e capital humano, dentre outras ações nesta direção, sendo sua meta 17 a que coloca especial ênfase nesse tema (ONU, 2015).

\section{Resultados e Discussão}

\subsection{Caracterização da Fundação CEPEMA}

A instituição que será apresentada para o estudo realizado é a Fundação Cultural Educacional Popular em Defesa do Meio Ambiente (Fundação CEPEMA), sediada na cidade de Fortaleza, estado do Ceará, sendo uma organização não governamental (ONG) brasileira, iniciando suas atividades em 1989, na cidade de Sobral, Ceará, associada à Rede Terra do Futuro/Suécia e à Rede de ONGs da Mata Atlântica/Brasil, que trabalha por um desenvolvimento social e ecológico, envolvendo pequenos produtores de agricultura familiar, trabalhadores rurais, assentados de reforma agrária e jovens desempregados.

A Fundação CEPEMA é classificada como uma instituição de médio porte e sem fins lucrativos, desenvolvendo atividades de qualificação profissional em agricultura ecológica, cooperativismo, associativismo e educação popular, nos biomas Caatinga e Mata Atlântica. Atualmente, possui um quadro de colaboradores com 28 pessoas, sendo 12 não efetivas e sim prestadores de serviços autônomos e 16 voluntários. A entidade desenvolve parcerias com organizações governamentais, não governamentais, associações de pequenos produtores, sindicatos e entidades da sociedade civil (CEPEMA, 2017).

Em 1992, a Fundação CEPEMA implantou um Centro de Agricultura Ecológica (CAE) em uma propriedade rural de 30 hectares, em Sobral, Ceará, onde foi possível desenvolver as práticas de agricultura ecológica em dois subsistemas: sequeiro e irrigável. A partir daí, a Fundação CEPEMA deu os seus primeiros passos para intensificar o desenvolvimento dos seus projetos, que, até hoje, são implementados, havendo uma constante atuação da instituição, tanto no campo como na cidade, no decorrer dos seus 30 anos de existência.

Ao longo desses anos, a Fundação CEPEMA foi reconhecida também através da mídia nacional e internacional. As principais reportagens foram: vídeo reportagem no programa Globo Rural da Rede Globo de Televisão em 2000, com reapresentação em 2001 e tempo de duração de 18 minutos; Programa Tempo de Qualificar da TVE do Rio de Janeiro, em 2000 com reapresentação em 2001 e tempo de duração de 12 minutos; reportagem escrita na revista SVERIGE NATUR/Suécia, no ano de 1999, com quatro páginas de reportagem (CEPEMA, 2017).

A Fundação CEPEMA tem como missão promover o desenvolvimento social e ecológico nas perspectivas ambiental, econômica e político-cultural, através de formações com base na agroecologia, para comunidades urbanas e rurais, sem qualquer discriminação de sexo, cor, religião ou preferência partidária. Sua atuação geográfica no Ceará, além de Fortaleza e região metropolitana, engloba vários municípios como, por exemplo, Baturité, Mulungu, Quixadá, Quixeramobim, Tianguá, Viçosa do Ceará, Mauriti, São Benedito, dentre outros.

Ao se analisar a missão da Fundação CEPEMA apresentada acima, conclui-se que a definição teórica de Terceiro Setor, adotada por Melo Neto e Froes (2001) associada à colaboração conceitual de Falconer (1999) e resumida na noção de um ambiente institucional privado com finalidades voltadas para a criação ou distribuição de bens e serviços públicos, ou seja, o público não-estatal, abrange o cerne da atuação da entidade. 
Os objetivos da instituição têm como cerne a educação popular, o desenvolvimento sustentável, a agricultura ecológica, o associativismo, a arte e cultura. Eles são elencados pela organização em sete tópicos da seguinte forma:

- Fortalecer a agricultura familiar dentro da perspectiva da agricultura ecológica, trabalhando diretamente com as associações de pequenos (as) produtores (as) e produtoras rurais;

- Disseminar a prática da agricultura ecológica urbana e rural, utilizando como instrumento a formação através da educação popular;

- Contribuir no fortalecimento da segurança alimentar e nutricional, através da agroecologia e da construção de sistemas agroflorestais;

- Incentivar a organização de trabalhadores e trabalhadoras do campo e da cidade, estimulando o cooperativismo, o associativismo e a comercialização solidária de produtos agroecológicos;

- Promover o resgate dos valores e saberes, através da valorização da arte e cultura;

- Desenvolver atividades na área de comunicação, tendo em vista a produção e veiculação de programas radiofônicos educativos; elaboração de vídeos e produção de material didático;

- Realizar intercâmbio com Entidades Governamentais ou Não-Governamentais no âmbito local, nacional e internacional, com a finalidade de trocas de experiências em educação, comunicação, agricultura ecológica, mantendo-se, porém, a independência e autonomia da Fundação.

Desde suas origens, a estruturação e a gestão organizacionais da Fundação CEPEMA articulam redes de cooperação institucional para a realização de suas atividades, como uma prática de governança em permanente evolução. Logo na sua criação, recebeu um aporte financeiro da Rede Internacional Terra do Futuro (Framtidsjorden), com sede em Estocolmo, Suécia, estabelecendo, também nessa época, uma parceria com o Fundo das Nações Unidas para a Infância (UNICEF), organismo de cooperação multilateral pertencente ao Sistema Organização das Nações Unidas (ONU). Isso permitiu a execução de um projeto de educação direcionado para crianças residentes na Fazenda de Todos Nós, em Sobral/CE. Embora o clima na região nordeste do Brasil seja predominantemente seco (Morais; Gomes; Lemos Filho; Silva; \& Facundo, 2020), a região atendida está dentro do Perímetro Irrigado Ayres de Souza, que pertence ao Departamento Nacional de Obras Contra as Secas (DNOCS), órgão do governo federal brasileiro.

Portanto, no que concerne à perspectiva da governança e da gestão organizacional, a Fundação CEPEMA tem como foco o planejamento estratégico que priorize a sua sustentabilidade financeira e a articulação de redes estáveis de parceiros, que possibilitem a execução de suas atividades de forma consistente e a longo prazo. $\mathrm{O}$ aprimoramento da qualificação profissional de colaboradores e gestores é uma boa prática institucional que as organizações do Terceiro Setor enfrentam como um desafio para seu desenvolvimento organizacional. Pela análise da formação das equipes técnicas dos projetos e dos gestores da Fundação CEPEMA, verifica-se que a instituição também tem, como prioridade da sua gestão organizacional, a profissionalização gerencial de seus quadros, tanto na dimensão estratégica, como na tática e operacional.

Além de fomentar as alianças estratégicas e o fortalecimento dos meios de implementação e revitalização de parcerias (ODS 17), a Fundação CEPEMA atua em mais cinco Objetivos de Desenvolvimento Sustentável, os ODSs 2, 5, 12, 13 e 15. Portanto, a instituição tem a expertise ideal para o estudo de caso que é objeto desse artigo.

\subsection{Critérios de alianças estratégicas da Fundação CEPEMA}

Como organização do Terceiro Setor, a formação e gestão de alianças estratégicas têm sido, desde a fundação da CEPEMA, uma prioridade que a instituição definiu para a elaboração, a viabilização e a execução de seus projetos. De acordo com o que foi explicitado, já no seu nascedouro, a Fundação CEPEMA articulou uma aliança estratégica com stakeholders, 
envolvendo uma ONG internacional, um organismo de cooperação multilateral vinculado à $\mathrm{ONU}$, uma comunidade rural e um órgão governamental federal.

Desta forma, da análise dos resultados da atuação institucional da Fundação CEPEMA na criação de suas redes de parcerias, na constituição e gestão de suas alianças estratégicas, apreende-se que ela segue a vertente teórica mais abrangente do conceito de aliança estratégica, no qual as organizações buscam realizar seus projetos e alcançar suas metas e objetivos em cooperação permanente com um arco plural de stakeholders, assegurando, assim, a execução de atividades que, de outro modo, poderiam ser inexequíveis.

No decorrer de seus 30 anos de existência, de acordo com informações obtidas com um de seus gestores, no questionário de sondagem exploratória enviado para a instituição, a Fundação CEPEMA aprofundou sua estratégia de estabelecimento de alianças e ampliou, significativamente, o número de parceiros nacionais e internacionais. Segundo o gestor entrevistado, a organização nunca atuou isoladamente, não tendo realizado nenhum projeto sem parcerias ou alianças com outras entidades. Neste processo de formação e gestão de alianças estratégicas, cujos objetivos principais são assegurar a sobrevivência da organização, sua sustentabilidade financeira, a maior relevância da instituição em seu entorno social, a ampliação do número e da qualidade dos projetos desenvolvidos pela entidade, bem como aprimorar os resultados e os impactos obtidos pelos projetos executados, a Fundação CEPEMA implementou uma ampla diversificação de suas parcerias, tanto em nível local, nacional, como internacional.

Essa linha teórica mais abrangente do conceito de aliança estratégica implementada pela entidade articula vários arranjos institucionais de parcerias, com múltiplos possíveis níveis de cooperação entre os seus stakeholders (Klotzle, 2003). A Fundação CEPEMA também segue, em sua gestão de alianças estratégicas, a perspectiva teórica dos recursos empresariais, considerando o risco para a execução sustentável de suas ações, bem como as principais demandas por recursos para a consecução de seus objetivos institucionais. Com este objetivo estratégico, a Fundação CEPEMA estabeleceu sua participação em várias redes de cooperação interinstitucional em variados temas, algumas dessas redes com a atuação de entidades públicas e privadas de caráter local, nacional e internacional.

As principais redes de instituições nas quais a Fundação CEPEMA atua são: Rede de ONGs da Mata Atlântica (nacional); Rede Internacional Terra do Futuro (Suécia e América Latina); Conselho Gestor da Sabiaguaba (local); Conselho Estadual do Meio Ambiente (COEMA - Estado do Ceará); Rede de Agroecologia do Ceará (Rede ECOCEARÁ); Fórum Brasileiro de ONGs e Movimentos Sociais (nacional); Rede Cuidando da Cidade (internacional - Suécia e Brasil); e o PREVINA (Programa de Prevenção, Monitoramento, Controle de Queimadas e Combate aos Incêndios Florestais coordenado pela Secretaria do Meio Ambiente do Estado do Ceará - SEMA). Para lastrear sua articulação de alianças estratégicas, a Fundação CEPEMA definiu, como modelo gerencial de seus projetos, a expansão do número e a fidelização de seus stakeholders provenientes tanto do Terceiro Setor como oriundos de todas as esferas do poder público, assim como de consórcios de organismos de cooperação multilateral.

Portanto, a partir do exposto no parágrafo anterior, demonstra-se mais uma vez que a Fundação CEPEMA segue a linha teórica dos recursos empresariais. Logo, a organização tem como objetivo, na formação de suas parcerias estratégicas, a mobilização e a conquista de stakeholders, os quais possam atuar tanto em projetos específicos, mas de preferência, tendo como meta que eles sejam ou se tornem apoiadores da CEPEMA de longo prazo, que atuem, colaborando de maneira complementar e simultânea, no aporte de recursos financeiros, tecnológicos, físicos e organizacionais.

Neste esforço, a Fundação CEPEMA mobiliza, também, em suas parcerias, outros atores sociais da sociedade civil, como empresas, instituições públicas de educação, sindicatos de trabalhadoras e trabalhadores rurais, associações de agricultores familiares, associações de assentamentos, grupos de cultura das periferias urbanas e movimentos sociais do campo e da cidade. A lista de parceiros governamentais estratégicos, conforme relatos de dois gestores da Fundação CEPEMA, é 
bastante extensa, cerca de 16, contendo organizações do poder público de todos os níveis, federal, estadual e municipal, da administração direta e indireta (empresas públicas, autarquias e empresas de economia mista), demonstrando a capacidade de articulação da organização no estabelecimento de suas parcerias com o Primeiro Setor, a saber, entes do Estado.

A quantidade de parceiros nacionais e internacionais da Fundação CEPEMA, pertencentes ao Terceiro Setor, também é bem numerosa. O seu principal parceiro é a Rede Internacional Terra do Futuro, organização não governamental sueca, com sede em Estocolmo, que financia projetos em diversos países. A Fundação CEPEMA é membro da Rede Terra do Futuro desde 1990. Suas outras alianças estratégicas com entidades do Terceiro Setor, segundo os informantes entrevistados, foram formadas com as seguintes instituições: Grupo Pereyra, Argentina; Kawsay, Bolívia; REDES (Rede de Ecologia Social), Uruguai; Comunidad del Sur, Uruguai; e Fundação Konrad Adenauer, Alemanha.

A mobilização de atores locais da sociedade civil onde os projetos da Fundação CEPEMA são desenvolvidos é uma prática de gestão presente nas articulações de suas alianças estratégicas. Como exemplos, pode-se citar os Sindicatos dos Trabalhadores e das Trabalhadoras Rurais de Viçosa do Ceará, de Ibiapina e de São Benedito; as Associações de Agricultores e Agricultoras da Agricultura Familiar desses mesmos municípios cearenses, como também o sindicato e as associações de Ubajara; e as Associações dos Assentamentos de reforma agrária, como as que atuam no Assentamento Santa Madalena, em Tianguá e no Assentamento Quiniporó, em Banabuiú.

Concernente à Agenda 2030 da ONU e aos seus Objetivos de Desenvolvimento Sustentável (ODSs), a Fundação CEPEMA tem um longo histórico de atuação e envolvimento com essa iniciativa. A partir das informações coletadas mediante a aplicação de questionário por escrito e entrevista semiestruturada com membros da gestão da organização, verifica-se que todas as ações dos projetos da Fundação CEPEMA estão relacionadas com a Agenda 2030 desde o ano de 2015.

\subsection{Análise de projeto, motivações dos parceiros e a relação com o ODS 17}

Em conexão com a Agenda 2030, as organizações, que incluem em sua governança e projetos quaisquer dos ODS's, devem ter como norte o estabelecimento de parcerias e a articulação de alianças com stakeholders, os quais possam assegurar uma longevidade tanto para as instituições, como para suas atividades e iniciativas.

Para tanto, o ODS 17 é estruturante de todos os demais objetivos da Agenda 2030, pois ao advogar o fortalecimento dos meios de implementação e revitalização da parceria global para o desenvolvimento sustentável, define como essencial a sustentabilidade de parcerias de longo prazo, como a forma mais eficaz de assegurar os meios de implementação dos projetos e das metas de viabilização da Agenda.

A busca por essa sustentabilidade institucional e pela sobrevivência financeira, que garanta a execução e o financiamento de projetos, com foco na qualidade dos impactos dos mesmos e na capacidade de serem desenvolvidos por longos prazos, passa por fatores organizacionais estratégicos como a cultura de planejamento, a competência de gestão, o aprimoramento das habilidades analíticas para avaliação de riscos e oportunidades, bem como o diagnóstico acurado das necessidades das comunidades e do entorno social, nos quais a entidade atua.

Assim, a meta 17.17., que propõe incentivar e promover parcerias públicas, público-privadas e com a sociedade civil eficazes, a partir da experiência das estratégias de mobilização de recursos dessas parcerias, é referência estrutural para os projetos e a atuação institucional da Fundação CEPEMA. Um dos seus projetos que explicita isso, com bastante ênfase, é o que articula questões sistêmicas, chamado Autogestão, Soberania Alimentar, Gênero e Mudanças Climáticas na Agricultura Familiar. Logo, nesse projeto multissetorial, constata-se que, em sua governança, a Fundação CEPEMA leva em consideração a teoria contingencial e a teoria baseada em recursos.

Este projeto articula alianças estratégicas com stakeholders públicos e privados tanto locais, nacionais, como internacionais. A rede internacional Terra do Futuro/Framtidsjorden na Suécia é a principal financiadora do projeto. Outros 
parceiros são os municípios, através das prefeituras, sindicatos de trabalhadores e trabalhadoras rurais, os assentamentos e as comunidades rurais, que atuam colaborando através de articulação e mobilização nas comunidades. Os municípios que participam do projeto são Ibiapina, Tianguá, Viçosa do Ceará, São Benedito e Quixadá.

O projeto tem como objetivo fortalecer a autogestão nos assentamentos agrários, comunidades rurais através da integração entre três eixos: soberania alimentar, gênero e agricultura adaptada às mudanças climáticas. Esses eixos são integrados nas atividades e no planejamento estratégico de cada assentamento e cada comunidade. A partir de dados obtidos relatados por um dos gestores da Fundação CEPEMA, as principais motivações mencionadas pelos stakeholders para participarem de alianças e parcerias em seus projetos são, além da visibilidade que a Fundação apresenta, sua capacidade técnica e capacidade de articulação com as organizações, a credibilidade, a estrutura física e a transparência em suas prestações de contas institucionais e na execução dos projetos (stakeholders accountability).

\section{Considerações Finais}

O presente estudo buscou caracterizar como as alianças estratégicas no Terceiro Setor são fatores importantes e podem contribuir no desenvolvimento de um projeto social de uma instituição, evidenciando as suas metas e os objetivos propostos na sua execução. Verificou-se que as alianças estratégicas da Fundação CEPEMA com os seus parceiros visaram atender as necessidades propostas nos projetos para suas avaliações e comprometimentos com sua missão, melhorando a qualidade de seus atendimentos para com seu público-alvo.

Esse artigo mostrou que as principais alianças estratégicas, para uma organização do Terceiro Setor, foram atendidas conforme a meta do Objetivo de Desenvolvimento Sustentável 17, no que diz respeito às parcerias estratégicas, considerando a meta 17 que se refere a incentivar e promover parcerias. Verifica-se que as principais alianças estratégicas da Fundação CEPEMA envolvem uma ONG internacional, a Framtidsjorden (Terra do Futuro), um conjunto de prefeituras em vários municípios do Ceará, sindicatos de trabalhadores e trabalhadoras rurais, associações de assentamentos oriundos da reforma agrária e redes de cooperação institucional com outras entidades do Terceiro Setor e do poder público, o que responde à pergunta inicial desse estudo.

Os objetivos mencionados nesse estudo foram atingidos: os principais fatores motivacionais para as organizações da sociedade civil realizarem parcerias estratégicas foram a capacidade técnica da instituição, a capacidade de articulação entres os parceiros, a sua credibilidade, a estrutura física da entidade para atender suas metas e a transparência e a governança em prestar contas ao parceiro; as alianças estratégicas do projeto estudado foram realizadas em parceria multissetorial e cooperação, através da Rede Terra do Futuro, uma vez que engloba experiências de diversos países, nos continentes da América do Sul, Ásia e Europa; e, por fim, correlacionar o caso de aliança estratégica institucional e do projeto social pesquisado com o Objetivo de Desenvolvimento Sustentável 17, tendo como escopo a sua meta 17.17, todas as ações dos projetos da Fundação CEPEMA estão relacionadas com a Agenda 2030.

Durante o primeiro semestre de 2020, a maior parte do mundo estava passando por uma pandemia, deixando todos em quarentena. Todas as empresas foram obrigadas a paralisar suas atividades de forma física. Portanto, não foi possível realizar a entrevista in loco, uma vez que dificultou o acesso à instituição, pois todas as suas ações ficaram voltadas para a forma virtual, como orientado pelos decretos definidos pelos órgãos do Estado.

Conclui-se que, no desenvolvimento das ações em meio à pandemia, estarão muitos desafios a serem enfrentados pela instituição, principalmente no que se referem às suas parcerias e alianças estratégicas, devido ao acesso restrito para uma articulação e uma cooperação mais intensiva. Com base nesse cenário que se desvela, sugere-se que novos estudos sejam desenvolvidos procurando analisar como as organizações do Terceiro Setor vêm revisando suas estratégias para superar mais um obstáculo encontrado no cenário da pandemia. Esse assunto, porém, não se esgotará apenas com estudos com a temática 
apresentada, de modo que outros trabalhos podem ser realizados para compreender se e como o atingimento das metas dos ODS, especialmente o 17, será afetada pela crise econômica observada nos anos de pandemia da COVID-19. Como sugestão adicional para novos (as) pesquisadores (as), indica-se como ponto de partida aplicar empiricamente subcritérios de sustentabilidade corporativa apresentados por Ikram, Zhang, Sroufe, e Ferasso (2020).

\section{Referências}

Alves, M. A. (2002). Terceiro Setor: as origens do conceito. Anais do Encontro da ANPAD (EnANPAD), 26.

Balestrin, A., \& Vargas, L. M. (2002). Evidências Teóricas para a Compreensão das Redes Inter organizacionais. Anais do Encontro de Estudos Organizacionais da ANPAD (EnEO), 2.

Bardin, L. (2016). Análise de conteúdo. Tradução Luís Antero Reto, Augusto Pinheiro. Editora 70.

Brasil (2017). Presidência da República, Programa das Nações Unidas para o Desenvolvimento (PNUD). Transformando nosso mundo: a Agenda 2030 para o Desenvolvimento Sustentável. Distrito Federal.

Bresser-Pereira, L. C. \& Grau, N.C. (1999). Entre o Estado e o Mercado: O Público Não Estatal. In: Bressser-Pereira, L. C., Grau, N. C. (Coord.). O Público Não-Estatal na Reforma do Estado. Editora FGV.

Brito, M. F. (2008). A cantiga das parcerias público-privadas na gestão urbana local.

CEPEMA. (2017). Manual de Procedimentos Administrativos. Fortaleza.

CEPEMA. (2020). Quem somos. Fortaleza.

Das, T. K., \& Teng, B.S. (1998). Between trust and control: developing confidence in partner cooperation in alliances. Academy of Management Review, 23, pp. 491-512.

Dyer, J., \& Kale, P. (2007). Relational capabilities: drivers and implications. Dynamic capabilities, Understanding strategic change in organizations, pp. 65-79.

Falconer, A. P. (1999). A promessa do Terceiro Setor: um estudo sobre a construção do papel das organizações sem fins lucrativos e do seu campo de gestão. Dissertação de Mestrado em Administração, Universidade de São Paulo, São Paulo, Brasil.

Fernandes, R. C. (1994). Privado, porém público. O terceiro setor na América Latina. (2 ed.). Rio de Janeiro: Relume-Dumará.

Gil, A. C. (1996). Como elaborar projeto de pesquisa. (3a ed.). Atlas.

Gil, A. C. (1999). Métodos e técnicas de pesquisa social. (5a ed.). Atlas.

Ikram, M., Zhang, Q., Sroufe, R., \& Ferasso, M. (2020). The Social Dimensions of Corporate Sustainability: An Integrative Fremework Including COVID-19 Insights. Revista Sustainability, 12 (20), 8747. https://doi.org/10.3390/su12208747

Jung, C. F. (2003). Metodologia Científica: Ênfase em Pesquisa Tecnológica. (3a ed). Departamento de Engenharia Mecânica, UFRGS.

Klotzle, M. C. (2002). Alianças estratégicas: conceito e teoria. Revista de Administração Contemporânea, 6 (1), 85-104.

Klotzle, M. C. (2003). O impacto da formação de alianças estratégicas no valor de mercado e no desempenho econômico-financeiro das empresas. Caderno de Pesquisas em Administração, 10 (4), 33-46.

Martins, G. A. (2006). Estudo de caso: uma estratégia de pesquisa. Atlas.

Melo Neto, F. P., \& Froes, C. (2001). Responsabilidade social e cidadania empresarial: a administração do terceiro setor. (2 ed.). Rio de Janeiro: Qualitymark.

Morais, M. A., Silva, G. F. Sizenando-Filho, F. A., Santos, A. A., \& Ismael, L. L. (2016) Aspectos socioeconômicos e ambientais do reuso de águas residuárias em uma comunidade rural localizada no município de Apodi-RN, Revista Verde de Agroecologia e Desenvolvimento Sustentável, 11 (4). http://dx.doi.org/10.18378/rvads.v11i4.4306

Morais, M. A., Gomes, F. B. M., Lemos Filho, L. C. A., Freire, G. S. S., Silva, G.de F., \& Facundo, A. L. (2020). Qualidade da água como instrumento para a gestão hídrica da Bacia Hidrográfica Piranhas-Açú (Rio Grande do Norte, Brasil). Revista Brasileira de Gestão Ambiental e Sustentabilidade, 7 (17). https://doi.org/10.21438/rbgas(2020)071733

Neves, J. L. (1996). Pesquisa qualitativa. Características, usos e possibilidades. Caderno de pesquisas em Administração, 1 (3), 1-5

Organização das Nações Unidas (ONU). (2015) The Future We Want, 1-52.

Pereira, A. S., Shitsuka, D. M., Parreira, F. J., \& Shitsuka, R. (2018). Metodologia da Pesquisa Científica. UFSM.

Salamon, L. (1997). Estratégias para o fortalecimento do Terceiro Setor. In: Ioschpe, E. (Coord.). $3^{\circ}$ Setor: desenvolvimento social sustentado. Paz e Terra.

Schilke, O., \& Goerzen, A. (2010). Alliance management capability: an investigation of the construct and its measurement. Journal of Management, 36 (5), pp. 1192-1219. 
Research, Society and Development, v. 10, n. 3, e48810313581, 2021

(CC BY 4.0) | ISSN 2525-3409 | DOI: http://dx.doi.org/10.33448/rsd-v10i3.13581

Teece, D. J. (1992). Competition, cooperation, and innovation: organizational arrangements for regimes of rapid technological progress. Journal of Economic Behavior and Organization, 18, pp. 1-25.

Vale, G. M. V., \& Lopes, H. E. G. (2010). Cooperação e alianças: Perspectivas Teóricas e suas Articulações no Contexto do Pensamento Estratégico. Revista de Administração Contemporânea, Curitiba, 14 (4), 722-737.

Viana, F. S. (2013). Formação e gestão de alianças estratégicas: um estudo multicasos no setor de construção civil.

Yin, R. K. (2015). Estudo de Caso: Planejamento e Métodos. (5 ed.). Bookman. 